\title{
Presynaptic Modulation of the Retinogeniculate Synapse
}

\author{
Chinfei Chen ${ }^{2}$ and Wade G. Regehr ${ }^{1}$ \\ ${ }^{1}$ Department of Neurobiology, Harvard Medical School, Boston, Massachusetts 02115, and 2Division of Neuroscience, Children's Hospital, Boston, \\ Massachusetts 02115
}

\begin{abstract}
Modulatory projections from brainstem nuclei and intrinsic thalamic interneurons play a significant role in modifying sensory information as it is relayed from the thalamus to the cortex. In the lateral geniculate nucleus (LGN), neurotransmitters released from these modulatory inputs can affect the intrinsic conductances of thalamocortical relay neurons, thus altering their firing properties. Here, we show that in addition to postsynaptic effects, neuromodulators such as serotonin (5-HT) and GABA can act presynaptically to regulate neurotransmitter release at the synapse between retinal ganglion cells (RGCs) and relay neurons in the LGN, the retinogeniculate synapse. Activation of $5 \mathrm{HT}_{1}$ and $\mathrm{GABA}_{\mathrm{B}}$ receptors significantly decreased EPSC amplitude. This inhibition was accompanied by a decrease in the extent of paired-pulse depression, suggesting that it is presynaptic in origin. In addition, fluorometric calcium measurements from retinal axon terminals labeled with Calcium Green-1 dextran revealed that $5 \mathrm{HT}_{1}$ and $\mathrm{GABA}_{\mathrm{B}}$ receptor agonists decreased presynaptic calcium influx. Taken together, our data indicate that serotonin and GABA can act presynaptically to decrease calcium influx at the retinogeniculate synapse and modify transmission of visual information in the LGN.
\end{abstract}

Key words: $\mathrm{GABA}_{\mathrm{B}}$ receptors; serotonin receptors; thalamus; visual system; presynaptic modulation; brainstem inputs

\section{Introduction}

Visual information is transmitted from the retina to the visual cortex via the connection between retinal ganglion cells (RGCs) and relay neurons in the lateral geniculate nucleus (LGN). Chemical messengers released by intrinsic neurons and brainstem projections can modify visual information that passes through the LGN (Steriade et al., 1997). In many cases, these neuromodulators affect membrane conductances of relay neurons. Cholinergic, serotonergic, and noradrenergic projections from the brainstem act on ion conductances of relay neurons to depolarize the cell, thus enhancing its activity (McCormick and Bal, 1994; Steriade et al., 1997). In contrast, activation of postsynaptic $\mathrm{GABA}_{\mathrm{B}}$ receptors by inhibitory neurons hyperpolarizes relay neurons and decreases their firing rates (Crunelli and Leresche, 1991).

On the basis of the widely observed presynaptic actions of many neuromodulators (Miller, 1998), it is likely that many chemical messengers also act presynaptically to regulate release at the retinogeniculate synapse. Little, however, is known of its role in the transmission of visual information at this synapse. Presynaptic inhibition may help to explain the observed effects of neuromodulators on visually evoked responses of relay neurons that are not accounted for by the known mechanisms of postsynaptic modulation. For example, in rats, stimulation of serotonergic inputs from the dorsal raphe nucleus or iontophoretic application of serotonin (5-HT) in the LGN in vivo decreases the response of relay neurons evoked by light or optic tract stimulation (Yoshida et al., 1984; Marks et al., 1987; Kayama et al., 1989).

Received Nov. 25, 2002; revised Feb. 10, 2003; accepted Feb. 11, 2003.

This work was supported by National Institutes of Health Grant K08 NS02056 to C.C. and R01-NS32405-01 to W.G.R. We thank Dawn Blitz, Solange Brown, Kaspar Vogt, and Daniel Seeburg for helpful comments on this manuscript.

Correspondence should be addressed to Chinfei Chen, The Children's Hospital, Division of Neuroscience, 300 Longwood Avenue, Boston, MA 02115. E-mail: chinfei.chen@tch.harvard.edu.

Copyright $\odot 2003$ Society for Neuroscience $\quad 0270-6474 / 03 / 233130-06 \$ 15.00 / 0$
These findings are difficult to reconcile with in vitro data demonstrating that serotonin increases the excitability of relay neurons (Steriade et al., 1997; Monckton and McCormick, 2002). One possible explanation is that presynaptic inhibition by 5-HT reduces relay neuron responses in vivo. There is precedent for such presynaptic modulation of the retinogeniculate synapse: activation of $\mathrm{GABA}_{\mathrm{B}}$ receptors results in inhibition at the retinogeniculate synapse (Emri et al., 1996). However, the mechanisms underlying this modulation are not well understood.

Here, we examine the actions of two neuromodulators, 5-HT and GABA, on transmission at retinogeniculate synapses. Using whole-cell voltage-clamp recordings, we examine the extent of presynaptic modulation. We find that activation of either 5-HT or $\mathrm{GABA}_{\mathrm{B}}$ receptors strongly inhibits synaptic strength. This inhibition is accompanied by a decrease in synaptic depression, indicating that it is presynaptic in origin. Moreover, by measuring presynaptic calcium transients, we find that inhibition of calcium influx into the terminals of retinal inputs contributes to the reduction in synaptic strength. Our findings demonstrate robust presynaptic modulation at the retinogeniculate synapse that can contribute to the regulation of transmission of visual information in the LGN.

\section{Materials and Methods}

Slice preparation and electrophysiology. LGN brain slices $(250 \mu \mathrm{m})$ from postnatal day 17-30 mice were obtained as described previously (Chen and Regehr, 2000). Whole-cell patch-clamp recordings from relay cells were achieved using 1.2-1.7 $\mathrm{M} \Omega$ glass electrodes containing the internal solution (in mM): $35 \mathrm{CSF}, 100 \mathrm{CsCl}, 10$ EGTA, 10 HEPES, 0.1 methoxyverapamil hydrochloride, $\mathrm{pH} 7.4$, and in an extracellular solution containing (in mM): $125 \mathrm{NaCl}, 2.5 \mathrm{KCl}, 2.6 \mathrm{NaH}_{2} \mathrm{PO}_{4}, 25$ glucose, 2 $\mathrm{CaCl}_{2}, 1 \mathrm{MgCl}_{2}, 0.020$ bicuculline, and $5 \mu \mathrm{M}$ 3-((R)-2-carboxypiperazine-4-yl)-propyl-1-phosphonic acid (R-CPP). Retinogeniculate synapses were extracellularly stimulated $(10-40 \mu \mathrm{A}, 0.2 \mathrm{msec})$ with a saline-filled glass electrode (5-10 $\mu \mathrm{m}$ tip diameter) placed in the optic tract. In most cases, the minimal stimulation response was activated by adjusting the stimulus intensity. We refer to this paradigm as single-fiber 
stimulation (Chen et al., 2002). In some cases, synaptic responses consisted of a large input and a small input that contributed $<10 \%$ of the synaptic current. Series resistance (3-6 M $\Omega$ ) was monitored to ensure constancy throughout the experiment. Constant bath perfusion $(\sim 3 \mathrm{ml} /$ min) was provided with a peristaltic pump through a $1.5 \mathrm{ml}$ recording chamber. All pharmacological agents were stored in stock solutions (Rbaclofen, R-CPP, 5-carboxamidotryptamine (5-CT), 2,3-dioxo-6-nitro1,2,3,4-tetrahydrobenzo[f] quinoxaline-7-sulfonamide (NBQX) in water; cyanopinodol, thapsigargin, CGP55845 in DMSO; Tocris, Ellisville, $\mathrm{MO}$ ) and diluted 1:1000-1:5000 immediately before bath application. 5 -HT solutions (Sigma, St. Louis, MO) were made fresh for each experiment. Data were acquired as described previously (Chen et al., 2002).

Calcium measurements. RGCs were labeled with calcium indicators using a protocol approved by the Animal Care and Use Committees at Harvard Medical School/Children's Hospital. Briefly, the mouse was placed in an enclosed chamber containing $250 \mu \mathrm{l}$ halothane. Once asleep, as tested by foot pad stimulation, a sharp glass electrode $(2-5 \mu \mathrm{m}$ tip diameter) filled with a solution that consisted of a $1: 1$ ratio of $20 \% \mathrm{w} / \mathrm{v}$ Calcium Green-1 dextran [molecular weight (MW) 3000] and 20\% w/v Texas Red dextran (MW 10,000; Molecular Probes, Eugene, OR) in $0.1 \%$ Triton X-100 was inserted into the retina. One microliter of the solution was pressure injected into the nasal and temporal regions of the retina (20 psi, 10-15 msec duration; Parker Instruments). After 2-5 d, the animal was killed to make brain slices. Examination of the slices under $60 \times$ objective (Olympus) revealed that retinogeniculate fibers but not postsynaptic cells were labeled. We found that Calcium Green-1 dextran provided a superior signal-to-noise ratio relative to the lower affinity fluo-4 dextran (Kreitzer et al., 2000; Haugland, 2002); thus, it was the preferred calcium-indicator dye for the present set of experiments. Stacked confocal z-series images were obtained as described previously (Kreitzer et al., 2000).

All fluorescence recordings were performed in the presence of the glutamate receptor antagonists NBQX $(5 \mu \mathrm{M})$ and CPP $(20 \mu \mathrm{M})$ using a 450-490 excitation/FT510 dichroic/510WB40 emission and 580DF15 excitation/600 dichroic long pass/610 long pass emission filter sets for Calcium Green-1 and Texan Red signals, respectively. Illumination was provided by a $150 \mathrm{~W}$ Xenon lamp (Optiquip) and gated with a transistor transistor logic pulse to an electromechanical shutter (Vincent Associates). Collected light from the labeled slice was digitized, and the relative change in fluorescence $(\Delta F / F)$ was calculated as described previously (Kreitzer et al., 2000). Experiments were conducted at $25^{\circ} \mathrm{C}$, and average measurements are reported as mean \pm SEM.

\section{Results}

We examined GABAergic and serotonergic modulation of the retinogeniculate synapse in a mouse brain slice that contained retinal fibers of the optic tract and the LGN. Experimental conditions were designed to minimize the known postsynaptic effects of these neurotransmitters (see Materials and Methods). In addition, the $\mathrm{GABA}_{\mathrm{A}}-$ receptor antagonist bicuculline $(20 \mu \mathrm{M})$ was included to eliminate contributions from the extensive inhibitory thalamic circuitry, and connections between the cortex and LGN were severed to eliminate cortical feedback (Chen and Regehr, 2000). Using this preparation, we could isolate and study synaptic transmission at the excitatory retinal input to relay neurons.

\section{GABAergic modulation of synaptic strength}

Stimulation of retinal fibers while the relay neuron was held at $-70 \mathrm{mV}$ evoked AMPA receptor (AMPAR) EPSCs that depressed significantly at an interstimulus interval (ISI) of $50 \mathrm{msec}$ (Chen et al., 2002). Bath application of the $\mathrm{GABA}_{\mathrm{B}}-$ receptor agonist baclofen reduced the synaptic strength of the first EPSC from $\sim 1$ to $0.05 \mathrm{nA}$ (Fig. $1 A$ ). This inhibition was reversed with bath application of the $\mathrm{GABA}_{\mathrm{B}}$ receptor antagonist CGP55845. The amplitudes of the first (A1) and second (A2) EPSCs and the
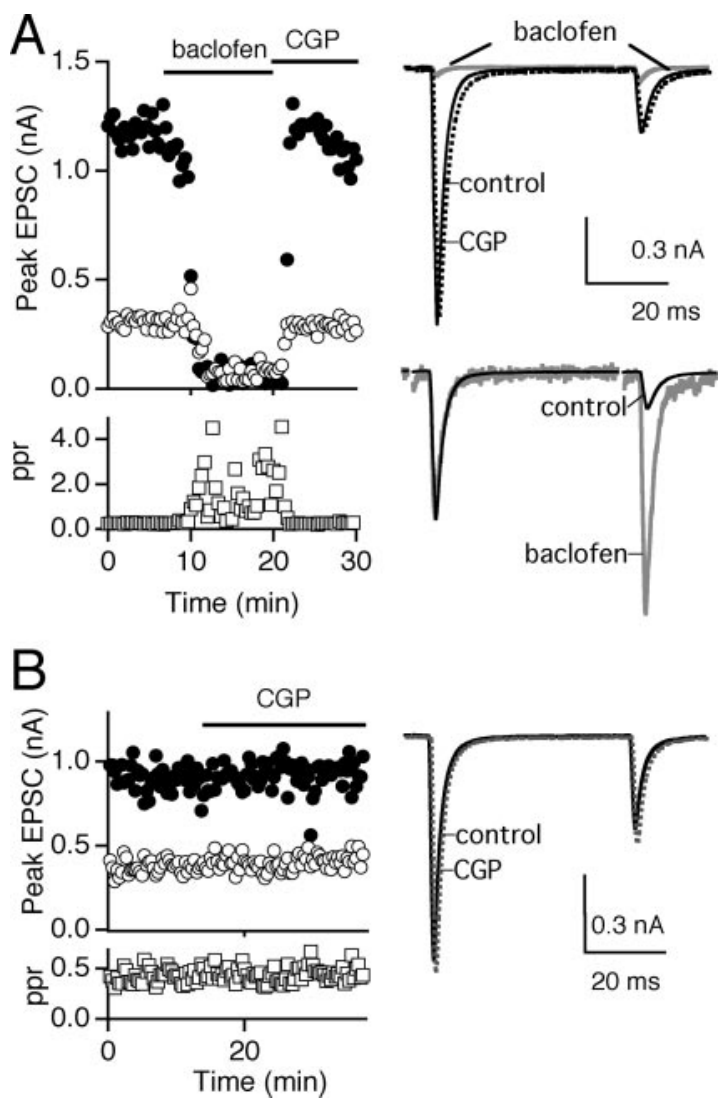

Figure 1. $\mathrm{GABA}_{\mathrm{B}}$ receptor-mediated modulation of the retinogeniculate synapse. $A$, The effects of baclofen (2 $\mu \mathrm{m})$ and (GP55845 (CGP) $(10 \mu \mathrm{m})$ on the synaptic response to pairs of pulses (ISI = $50 \mathrm{msec}$ ). Left, Time course of the first $(O)$ and second $(\bigcirc)$ peak AMPA EPSC amplitudes and the ppr ( $\square$ ). Right top, Average EPSCs are shown in control conditions (black trace), in baclofen (gray trace), and in (GP55845 (dashed trace). Right bottom, Pairs of EPSCs in control conditions and in baclofen (gray trace) are normalized to illustrate the change in ppr. $B$, Left, CGP55845 (10 $\mu \mathrm{m})$ alone does not change synaptic strength or ppr. Right, Overlay of average EPSCs in control conditions (black trace) and in CGP55845 (dashed trace). Traces are the average of three to five trials.

paired-pulse ratio $(\mathrm{ppr}=\mathrm{A} 2 / \mathrm{A} 1)$ are plotted as a function of time during exposure to these neuromodulators (Fig. 1A, left). An overlay of the average currents elicited in control conditions and in the presence of baclofen and CGP55845 shows that in addition to its effect on synaptic strength, baclofen reduced the extent of synaptic depression (Fig. $1 A$, top right). This is emphasized in Figure $1 A$ (bottom right), in which EPSCs in control conditions and in the presence of baclofen are normalized to the amplitude of the first EPSC to compare the relative strength of the second EPSC. The effect of baclofen was dose dependent, with $200 \mathrm{nM}, 2$ $\mu \mathrm{M}, 10 \mu \mathrm{M}$, and $20 \mu \mathrm{M}$ baclofen inhibiting EPSC amplitude to $54.1 \pm 5.8 \%(n=4), 4.1 \pm 1.4 \%(n=7), 6.1 \pm 1.2 \%(n=4)$, and $6.4 \pm 1.9 \%(n=4)$ of control, respectively. Baclofen inhibition was readily reversible after washout in the presence of the $G_{A B A}$ antagonist CGP55845. The average ppr (ISI $=50 \mathrm{msec}$ ) increased from $0.50 \pm 0.06$ in control to $1.52 \pm 0.20$ in $2 \mu \mathrm{M}$ baclofen $(n=6)$.

These results confirm that $\mathrm{GABA}_{\mathrm{B}}$ receptor activation modulates the retinogeniculate synapse. Using voltage-clamp recordings, we found that the extent of this inhibition was remarkable; very low concentrations of baclofen were sufficient to reduce transmission to $<5 \%$ of control. The changes in ppr observed in voltage clamp suggest that this inhibition arises primarily from presynaptic mechanisms.

To address the possibility that a baseline level of tonic inhibi- 

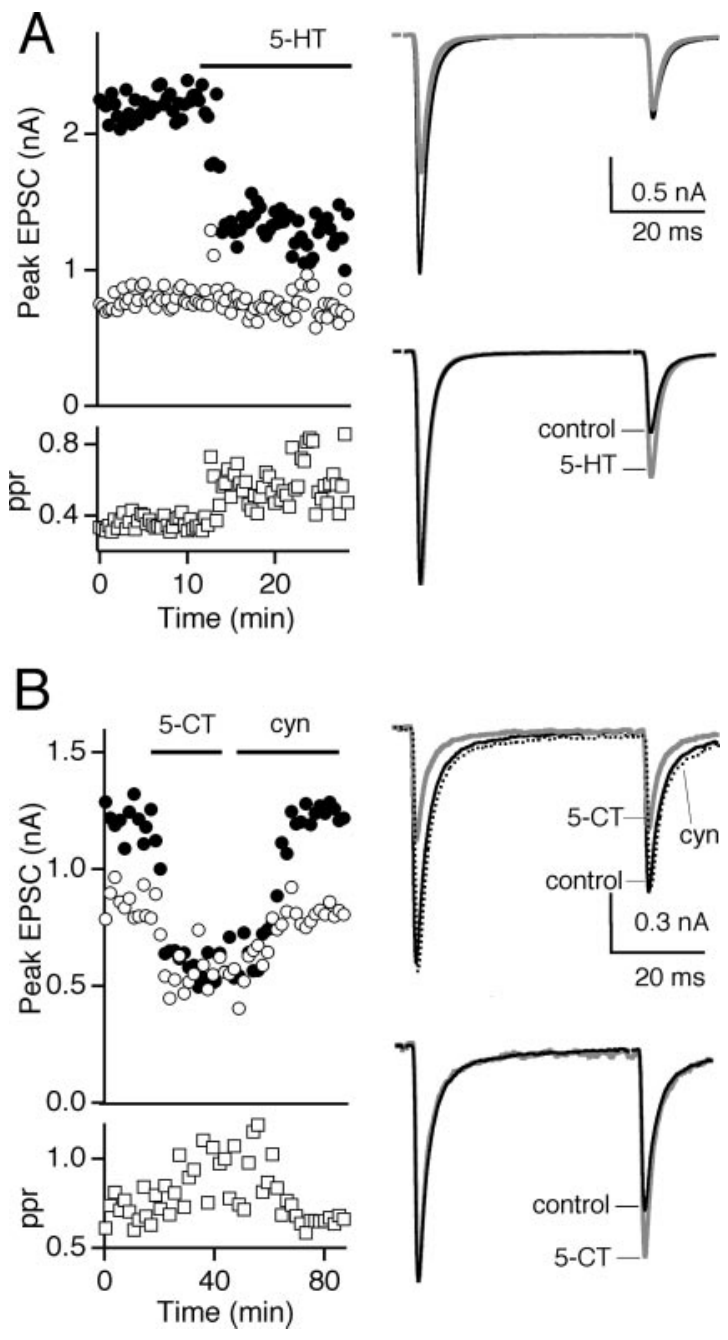

Figure 2. Serotonergic modulation of synaptic strength. Effects of $10 \mu \mathrm{M} 5-\mathrm{HT}(A)$ and $1 \mu \mathrm{M}$ 5-CT and $10 \mu \mathrm{m}$ cyanopindolol ( $B$ ) on the pairs of AMPAR EPSCs are shown. Left, Time course of the first $(\bigcirc)$ and second $(\bigcirc)$ peak AMPA EPSC amplitudes and ppr $(\square)$. Right top, Average pairs of EPSCs in control conditions (black trace), during bath application of the agonist (gray trace), and in B, the antagonist cyanopindolol (cyn, dashed trace). Right bottom, Pairs of EPSCs in control conditions and in the presence of 5 -HT receptor agonists are normalized to compare the ppr. Traces are the averages of three to five trials.

tion via $\mathrm{GABA}_{\mathrm{B}}$ receptors is present at the retinogeniculate synapse, we studied the effects of antagonizing $\mathrm{GABA}_{\mathrm{B}}$ receptors. Bath application of CGP55845 alone did not alter the response to pairs of stimuli (Fig. 1B). On average, the EPSC amplitude in CGP55845 was $98.5 \pm 2.6 \%$ of control $(n=4)$. This indicates that for our experimental conditions, extracellular levels of GABA do not lead to significant presynaptic inhibition.

\section{Serotonergic modulation of the retinogeniculate synapse}

Activation of serotonin receptors also modulated the retinogeniculate synapse (Fig. 2A). 5-HT $(10 \mu \mathrm{M})$ reduced synaptic strength to $43 \pm 8 \%(n=5)$. In addition, ppr (ISI $=50 \mathrm{msec})$ increased from $0.31 \pm 0.03$ in standard conditions to $0.62 \pm 0.06$ in the presence of 5-HT $(n=5)$, suggesting a presynaptic locus of action for $5-\mathrm{HT}$. The $5-\mathrm{HT}_{1}$ subclass of receptors has been shown to localize to the axon terminals in the mouse CNS (Boschert et al., 1994). Therefore, we examined the effects of 5-CT, a 5-HT $/$ $5-\mathrm{HT}_{7}$ receptor agonist at the retinogeniculate synapse. As shown in Figure 2 B, 5-CT also inhibited transmission, and this was re- versed with the $5-\mathrm{HT}_{1}$ receptor antagonist cyanopindolol. The effect of 5-CT was dose dependent, with $5 \mathrm{nM}, 1 \mu \mathrm{M}$, and $10 \mu \mathrm{M}$ 5 -CT reducing EPSC amplitude to $65 \pm 7 \%(n=4), 31 \pm 6 \%$ $(n=7)$, and $36 \pm 5 \%(n=4)$, respectively. 5-CT $(1 \mu \mathrm{M})$ also inhibited EPSC amplitude to $40 \pm 6 \%(n=5)$ in the presence of CGP55845A $(10 \mu \mathrm{M})$, indicating that the inhibition did not reflect an indirect effect on GABAergic transmission. In addition, 1 $\mu \mathrm{M}$ 5-CT decreased synaptic depression and increased ppr (ISI = $50 \mathrm{msec})$ from $0.46 \pm 0.06$ to $1.0 \pm 0.13(n=7)$.

\section{Fluorometric calcium measurements from retinal axon terminals}

The effects of GABAergic and serotonergic modulation on paired-pulse plasticity strongly suggest that these neuromodulators act presynaptically to influence synaptic strength. To more clearly define a presynaptic or postsynaptic site of action and to clarify the mechanism underlying this modulation by $\mathrm{GABA}_{\mathrm{B}}$ and serotonin receptors, we tested whether these neuromodulators reduce presynaptic calcium influx at retinal axon terminals. These experiments were done under conditions that eliminated both excitatory and inhibitory synaptic transmission.

The anatomical characteristics of the retinogeniculate connection are notable for the long distance between the soma of the presynaptic RGCs and the postsynaptic relay neuron. We took advantage of these features to selectively label RGC boutons with a calcium-sensitive indicator. Calcium Green-1 and Texas Red dextrans were injected into the retina of anesthetized mice (see Materials and Methods). Texas Red aided in the identification of labeled retinal fibers because background fluorescence of the brain slice overlapped with the emission spectrum of Calcium Green-1 (Kreitzer et al., 2000). This in vivo labeling technique allowed retinogeniculate fibers to be labeled without unwanted labeling of other projections to the LGN, such as brainstem and corticothalamic inputs.

Labeling with dextran-conjugated indicators was best visualized with Texas Red fluorescence. In general, whole-eye fills with dextran dyes resulted in patchy labeling of the LGN when compared with that seen with the lipophilic indicator Di-I (Chen and Regehr, 2000), suggesting that a smaller population of RGCs was labeled (Fig. 3A, left). A high-power view of an intensely labeled region shows that the fluorescence arises from fibers and their associated presynaptic boutons (Fig. $3 A$, right). These boutons vary in size (Fig. $3 A$, arrows), consistent with electron microscopy studies that found RGC terminals to range from 2 to $6 \mu \mathrm{m}$ in diameter (Rafols and Valverde, 1973; Hamos et al., 1987). Because a single retinal input can give rise to tens to hundreds of boutons, the fluorescence arises primarily from synaptic boutons (Rafols and Valverde, 1973; Hamos et al., 1987).

To use the selective calcium indicator labeling of retinal inputs as a method to monitor presynaptic calcium changes, we first characterized the stimulus-evoked fluorescence signal. Optic tract stimulation produced Calcium Green- $1 \Delta F / F$ transients that were measured from a 150-200 $\mu \mathrm{m}$ diameter spot in the LGN. These signals are the aggregate fluorescence changes from many activated retinal inputs. The responses to the one and two stimuli are overlaid in Figure $3 B$ (left). The second stimuli evoked a slightly smaller incremental increase in $\Delta F / F$ than did the first (Fig. 3B, right). This is consistent with a sublinear relationship between calcium entry and the $\Delta F / F$ signal measured with Calcium Green-1 dextran, which has a $K_{\mathrm{d}}$ of $540 \mathrm{~nm}$ (Haugland, 2002). As a result, Calcium Green-1 dextran slightly underestimates the extent to which various manipulations affect calcium entry. 


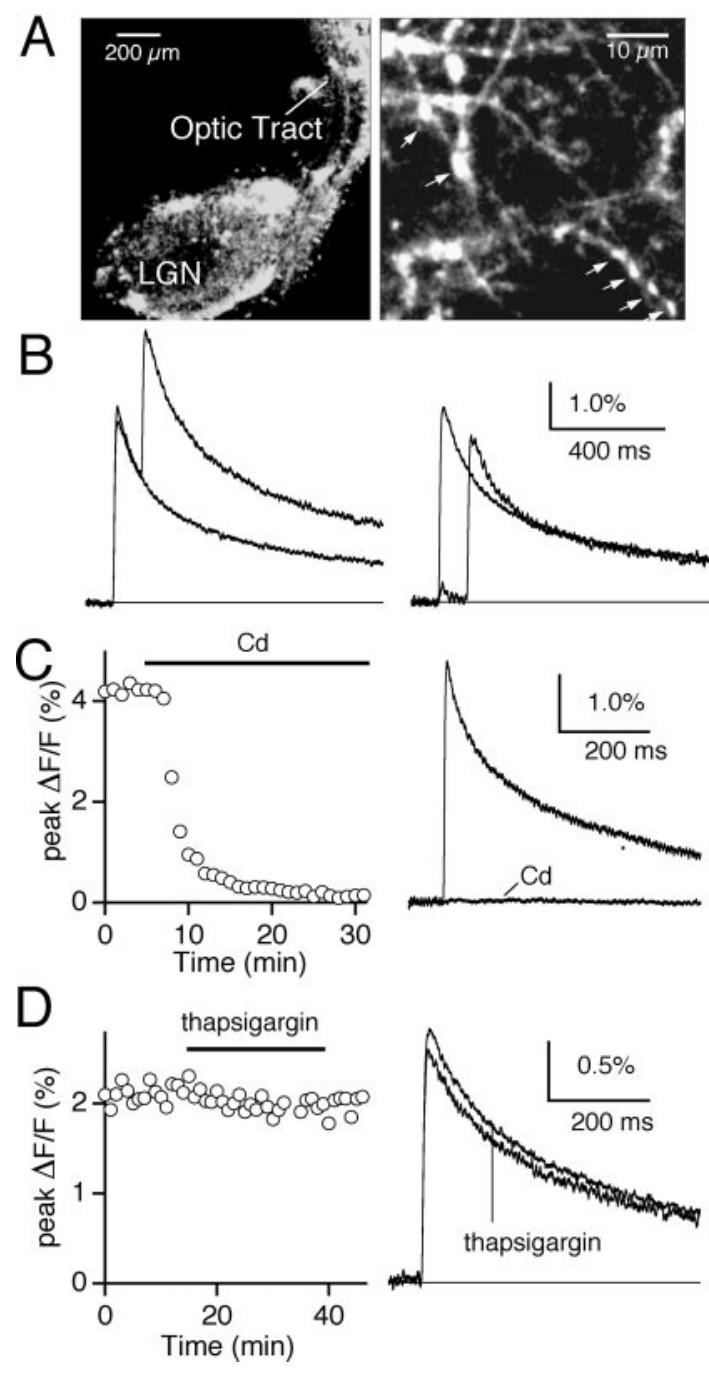

Figure 3. Monitoring presynaptic calcium at the retinogeniculate synapse. $A$, Labeling in the LGN slice at low (left) and high (right) magnifications after injection of Calcium Green-1 and Texas Red dextran into the contralateral retina. Texas Red fluorescence images allow visualization of individual boutons (arrows). $B$, Left, The $\Delta F / F$ signal measured in response to a single stimulus and a pair of optic tract stimuli; $|S|=50 \mathrm{msec}$. Right, The incremental increase in $\Delta F / F$ produced by the second stimuli, obtained by subtracting the response to a single stimulus from that to a pair of stimuli, is compared with the $\Delta F / F$ signal produced by the first stimulus. Effects of $100 \mu \mathrm{m}$ cadmium chloride $(C)$ and $10 \mu \mathrm{m}$ thapsigargin $(D)$ on the average time course of the peak $\Delta F / F$ signal (left) and on the $\Delta F / F$ transients (right). Traces are the average of three to five trials.

We also examined the source of the calcium that gave rise to the $\Delta F / F$ signals. Bath application of cadmium $(100 \mu \mathrm{M})$, which blocks calcium influx through voltage-dependent calcium channels (Mintz et al., 1995), inhibited the average evoked $\Delta F / F$ signal to $-1 \pm 6.1 \%$ of control $(n=4)$ (Fig. $3 C$ ). Disruption of signaling through internal calcium stores by blocking the pump that loads these stores with thapsigargin $(10 \mu \mathrm{M})$ had minimal effects on the $\Delta F / F$ signal (Fig. $3 D$ ). The $\Delta F / F$ signal was $92.8 \pm 0.8 \%$ of control in the presence of thapsigargin $(n=3)$. Together, these experiments indicate that the stimulus-evoked presynaptic calcium transients arise primarily from influx through voltagegated calcium channels.

\section{Modulation of the $\Delta F / F$ signal}

To examine the sensitivity of Calcium Green-1 dextran to changes in presynaptic calcium influx, we tested the effect of
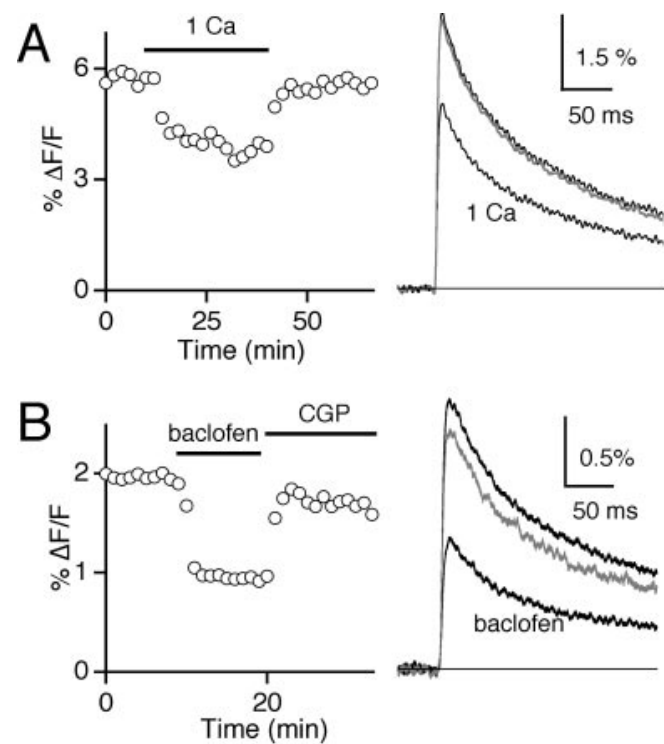

C

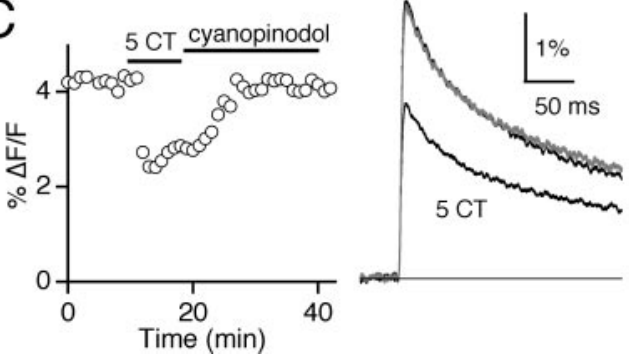

Figure 4. Modulation of presynaptic calcium entry. Lowering $\mathrm{Ca}_{\mathrm{e}}(A)$ or bath application of $2 \mu \mathrm{m}$ baclofen $(B)$ or $1 \mu \mathrm{m}$ 5-CT (C) decreased the evoked Calcium Green- $1 \Delta F / F$ signal. Shown are the time course of the peak $\Delta F / F$ signal (left) and the $\Delta F / F$ signals (right) recorded before, during, and after (gray traces) the indicated experimental manipulation.

altering calcium entry by decreasing extracellular calcium levels $\left(\mathrm{Ca}_{\mathrm{e}}\right)$. Figure $4 A$ shows that changing $\mathrm{Ca}_{\mathrm{e}}$ from 2 to $1 \mathrm{~mm}$ reversibly decreased the $\Delta F / F$ amplitude from 5.6 to $3.7 \%$. On average, in $1 \mathrm{mM} \mathrm{Ca}_{\mathrm{e}}$, the $\Delta F / F$ amplitude decreased to $64.5 \pm 2.0 \%(n=$ 4) of that in $2 \mathrm{~mm} \mathrm{Ca}_{\mathrm{e}}$. This is similar to the reduction in calcium entry resulting from decreasing $\mathrm{Ca}_{\mathrm{e}}$ from 2 to $1 \mathrm{~mm}$ observed at other synapses (Mintz et al., 1995; Sakaba and Neher, 2001; Foster et al., 2002). Thus, changes in presynaptic calcium influx can be detected using this in vivo technique of labeling RGC axon terminals.

We next determined whether $\mathrm{GABA}_{\mathrm{B}}$ receptors or $5-\mathrm{HT}_{1}$ receptors inhibit transmission by reducing presynaptic calcium entry. Agonists for both the $\mathrm{GABA}_{\mathrm{B}}$ (Fig. $4 B$ ) and 5-HT $\mathrm{HT}_{1}$ receptors (Fig. $4 C$ ) decreased the $\Delta F / F$ signal from retinal axon terminals in the LGN. The time course of the peak $\Delta F / F$ amplitude (left) and average $\Delta F / F$ traces (right) are shown for control conditions and in the presence of agonist and antagonist. On average, $2 \mu \mathrm{M}$ baclofen reduced the peak $\Delta F / F$ transient to $53.0 \pm 2.5 \%$ of control $(n=6)$, and $1 \mu \mathrm{M} 5$-CT inhibited the $\Delta F / F$ signal to $66.0 \pm 2.3 \%$ $(n=4)$ of control. These findings indicate that at the retinogeniculate synapse, inhibition of presynaptic calcium entry is the primary mechanism underlying presynaptic modulation arising from either $\mathrm{GABA}_{\mathrm{B}}$ or $5-\mathrm{HT}_{1}$ receptor activation.

\section{Discussion}

Our results show that modulation by neurotransmitters of the retinogeniculate synapse at a presynaptic site can contribute significantly to modifying incoming visual information to the thal- 
amus. The activation of 5-HT and $\mathrm{GABA}_{\mathrm{B}}$ receptors reduces neurotransmitter release from retinal axon terminals and decreases synaptic depression primarily by lowering presynaptic calcium influx. Thus, in addition to the postsynaptic actions of these neuromodulators that have been described extensively (McCormick and Bal, 1994; Steriade et al., 1997), these neurotransmitters inhibit transmission presynaptically at retinogeniculate synapses.

\section{$\mathrm{GABA}_{\mathrm{B}}$ receptor-mediated presynaptic modulation of retinogeniculate synapses}

The extent of modulation by activation of presynaptic $\mathrm{GABA}_{\mathrm{B}}$ receptors suggests that it provides a particularly important regulatory mechanism at the retinogeniculate synapse. Although presynaptic inhibition by $G_{A B A}$ receptors is widespread in the CNS, the retinogeniculate synapse is one of the most strongly inhibited. For comparison, saturating inhibition by $\mathrm{GABA}_{\mathrm{B}}$ activation reduces the EPSC amplitudes at the retinogeniculate synapse, the calyx of Held, the synapse between perforant path to dentate gyrus in the hippocampus, and parallel fiber to Purkinje cell in the cerebellum to $5,18,55$, and $6 \%$ of control, respectively (Lanthorn and Cotman, 1981; Dittman and Regehr, 1996; Takahashi et al., 1998). We have shown that decreased presynaptic calcium entry contributes to this modulation, but the extent of the inhibition suggests that additional mechanisms may also contribute, such as presynaptic modulation downstream from calcium influx (Dittman and Regehr, 1996).

Under physiological conditions, it is likely that inhibitory interneurons within the LGN and those in nucleus reticularis release the GABA that leads to presynaptic inhibition of the retinogeniculate synapse. Anatomical studies in the LGN of cat, rat, and mouse show that inhibitory nerve endings can be found in close proximity to retinal axon terminals (Rafols and Valverde, 1973; Hamos et al., 1985; Steriade et al., 1997), making it possible for GABA to spill over from inhibitory synapses to presynaptic sites on excitatory inputs. In our slice preparation of the mouse LGN, we do not find significant tonic activation of presynaptic $G_{A B A}$ receptors, in contrast to previous studies in rat (Emri et al., 1996). This difference may reflect the relatively low levels of activity in our experimental conditions.

Previous studies have shown that this network of inhibitory thalamic interneurons can regulate the resting membrane potential of relay neurons (Crunelli and Leresche, 1991; Steriade et al., 1997). Here we have shown that presynaptic modulation by $\mathrm{GABA}_{\mathrm{B}}$ receptors decreases synaptic depression. This change in short-term plasticity may alter the range of RGC firing rates that are effective in relaying visual information (Abbott et al., 1997; Brenowitz et al., 1998). In addition, RGC bursts, which occur in response to visual stimulation, may result in the activation of presynaptic $G_{A B A}$ receptors that contribute to a negative feedback mechanism. Moreover, it is likely that population discharges of interneurons that occur during thalamic oscillations during sleep (Steriade et al., 1997) can lead to presynaptic $\mathrm{GABA}_{\mathrm{B}}$ receptor activation and subsequent inhibition of retinogeniculate synapses.

\section{5-HT receptor-mediated presynaptic modulation of retinogeniculate synapses}

Serotonin has been shown to inhibit neurotransmission at other excitatory CNS synapses, including the retinal input to the superior colliculus and the thalamocortical input to the somatosensory cortex (Mooney et al., 1994; Rhoades et al., 1994; Fouquet et al., 2002). On the basis of the lack of direct action by serotonin on the postsynaptic neuron and changes in ppr, these studies con- cluded that the neuromodulator acted on a presynaptic site. In the majority of cases, this effect has been associated with the $5-\mathrm{HT}_{1}$ subclass of receptors, consistent with its localization on axon terminals of many CNS neurons (Boschert et al., 1994). Here we show that activation of the $5-\mathrm{HT}_{1}$ receptor subclass at the retinogeniculate synapse inhibits presynaptic Ca influx. Modulation of $\mathrm{Ca}$ entry may be a common mechanism by which serotonin acts presynaptically at other CNS synapses.

There are multiple distinct actions of 5-HT in the LGN. 5-HT has been shown to depolarize relay neurons and increase their firing by shifting the voltage dependence of the activation of the hyperpolarization-activated cation channel, $\mathrm{I}_{\mathrm{h}}$, (McCormick and Pape, 1990). In addition, 5-HT inhibits relay neurons indirectly by enhancing the activity of intrinsic inhibitory interneurons (Monckton and McCormick, 2002). Our results show that 5-HT activates presynaptic receptors and decreases the strength of the sensory afferent input. Taken together, the combination of these multiple actions can result in a net decrease in relay neuron response to optic tract stimulation in certain situations, consistent with previous in vivo studies (Yoshida et al., 1984; Marks et al., 1987; Kayama et al., 1989).

In summary, our study shows that mechanisms of presynaptic inhibition are present and powerful in the visual pathway. Neuromodulatory inputs from the brainstem and intrinsic interneurons can significantly alter transmission at the retinogeniculate synapse by reducing presynaptic calcium influx. Thus, in concert with the intrinsic inhibitory circuitry of the thalamus, the membrane conductances of relay neurons, corticothalamic inputs, and short-term synaptic plasticity of the retinogeniculate synapse (McCormick and Bal, 1994; Steriade et al., 1997; Chen et al., 2002), mechanisms of presynaptic modulation can influence the relay of visual information in the mammalian CNS.

\section{References}

Abbott LF, Sen K, Varela JA, Nelson SB (1997) Synaptic depression and cortical gain control. Science 275:220-222.

Boschert U, Amara DA, Segu L, Hen R (1994) The mouse 5-hydroxytryptaminelB receptor is localized predominantly on axon terminals. Neuroscience 58:167-182.

Brenowitz S, David J, Trussell L (1998) Enhancement of synaptic efficacy by presynaptic $\mathrm{GABA}_{\mathrm{B}}$ receptors. Neuron 20:135-141.

Chen C, Regehr WG (2000) Developmental remodeling of the retinogeniculate synapse. Neuron 28:955-966.

Chen C, Blitz DM, Regehr WG (2002) Contributions of receptor desensitization and saturation to plasticity at the retinogeniculate synapse. Neuron 33:779-788.

Crunelli V, Leresche N (1991) A role for GABAB receptors in excitation and inhibition of thalamocortical cells. Trends Neurosci 14:16-21.

Dittman JS, Regehr WG (1996) Contributions of calcium-dependent and calcium-independent mechanisms to presynaptic inhibition at a cerebellar synapse. J Neurosci 16:1623-1633.

Emri Z, Turner JP, Crunelli V (1996) Tonic activation of presynaptic GABA(B) receptors on thalamic sensory afferents. Neuroscience 72:689-698.

Foster KA, Kreitzer AC, Regehr WG (2002) Interaction of postsynaptic receptor saturation with presynaptic mechanisms produces a reliable synapse. Neuron 36:1115-1126.

Fouquet C, Alvarez C, Seif I, Price D, Gaspar P, Cases O, Laurent A (2002) Activity-dependent presynaptic effect of serotonin $1 \mathrm{~B}$ receptors on the somatosensory thalamocortical transmission in neonatal mice. J Comp Neurol 442:331-347.

Hamos JE, Van Horn SC, Raczkowski D, Uhlrich DJ, Sherman SM (1985) Synaptic connectivity of a local circuit neurone in lateral geniculate nucleus of the cat. Nature 317:618-621.

Hamos JE, Van Horn SC, Raczkowski D, Sherman SM (1987) Synaptic circuits involving an individual retinogeniculate axon in the cat. J Comp Neurol 259:165-192.

Haugland RP (2002) Handbook of fluorescent probes and research chemicals, Web Edition. Eugene, OR: Molecular Probes Inc. 
Kayama Y, Shimada S, Hishikawa Y, Ogawa T (1989) Effects of stimulating the dorsal raphe nucleus of the rat on neuronal activity in the dorsal lateral geniculate nucleus. Brain Res 489:1-11.

Kreitzer AC, Gee KR, Archer EA, Regehr WG (2000) Monitoring presynaptic calcium dynamics in projection fibers by in vivo loading of a novel calcium indicator. Neuron 27:25-32.

Lanthorn TH, Cotman CW (1981) Baclofen selectively inhibits excitatory synaptic transmission in the hippocampus. Brain Res 225:171-178.

Marks GA, Speciale SG, Cobbey K, Roffwarg HP (1987) Serotonergic inhibition of the dorsal lateral geniculate nucleus. Brain Res 418:76-84.

McCormick DA, Bal T (1994) Sensory gating mechanisms of the thalamus. Curr Opin Neurobiol 4:550-556.

McCormick DA, Pape HC (1990) Noradrenergic and serotonergic modulation of a hyperpolarization-activated cation current in thalamic relay neurones. J Physiol (Lond) 431:319-342.

Miller RJ (1998) Presynaptic receptors. Annu Rev Pharmacol Toxicol 38:201-227.

Mintz IM, Sabatini BL, Regehr WG (1995) Calcium control of transmitter release at a cerebellar synapse. Neuron 15:675-688.

Monckton JE, McCormick DA (2002) Neuromodulatory role of serotonin in the ferret thalamus. J Neurophysiol 87:2124-2136.
Mooney RD, Shi MY, Rhoades RW (1994) Modulation of retinotectal transmission by presynaptic 5-HT1B receptors in the superior colliculus of the adult hamster. J Neurophysiol 72:3-13.

Rafols JA, Valverde F (1973) The structure of the dorsal lateral geniculate nucleus in the mouse. A Golgi and electron microscopic study. J Comp Neurol 150:303-332.

Rhoades RW, Bennett-Clarke CA, Shi MY, Mooney RD (1994) Effects of 5-HT on thalamocortical synaptic transmission in the developing rat. J Neurophysiol 72:2438-2450.

Sakaba T, Neher E (2001) Quantitative relationship between transmitter release and calcium current at the calyx of Held synapse. J Neurosci 21:462-476.

Steriade M, Jones EG, McCormick DA (1997) Thalamus. Oxford: Elsevier Science.

Takahashi T, Kajikawa Y, Tsujimoto T (1998) G-protein-coupled modulation of presynaptic calcium currents and transmitter release by a $\mathrm{GABA}_{\mathrm{B}}$ receptor. J Neurosci 18:3138-3146.

Yoshida M, Sasa M, Takaori S (1984) Serotonin-mediated inhibition from dorsal raphe nucleus of neurons in dorsal lateral geniculate and thalamic reticular nuclei. Brain Res 290:95-105. 